\title{
Speech Recognation Pada Pola Warna Dasar Merah Kuning Hijau Dengan Implementasi Sdk 5.1
}

\author{
Erwin Dwika Putra ${ }^{1}$, Noris Jastrawan ${ }^{2}$ \\ ${ }^{1}$ Fakultas Teknik, Universitas Muhammadiyah Bengkulu \\ Jl. Bali, Bengkulu 38119 \\ Email : erwindwikap@gmail.com \\ ${ }^{2}$ Fakultas Teknik, Universitas Muhammadiyah Bengkulu \\ Jl. Bali, Bengkulu 38119
}

\begin{abstract}
Sound can not propagate in space vacuum . These sound waves have valleys and hills, valleys and hills of the fruit will result in one cycle or period. This cycle takes place repeatedly, leading to the concept of frequency . Clearly, the frequency is the number of cycles that occur in one second . The unit of frequency is Hertz, abbreviated $\mathrm{Hz}$. Color can provide powerful information for object recognition . A simple real scheme and identification of matching the image based on the color histogram as proposed by Swain and Ballard . From this study, the authors conclude that the Speech SDK 5.1 is less able to recognize intonation delivered with a level of accuracy that is obtained is average success of $75 \%+65 \%+90 \%=$ $230 \%, 230 \% / 3=76.67 \%$.

Kata Kunci: Sound, Color, Recoginiton
\end{abstract}

Abstrak - Suara tidak bisa merambat dalam ruang hampa ruang . Gelombang suara memiliki lembah dan bukit-bukit, lembah dan bukit-bukit buah akan menghasilkan satu siklus atau periode. Siklus ini berlangsung berulang-ulang, yang mengarah ke konsep frekuensi . Jelas, frekuensi adalah jumlah siklus yang terjadi dalam satu detik. Satuan frekuensi adalah Hertz, Hz disingkat . Warna dapat memberikan informasi yang kuat untuk pengenalan obyek. Sebuah skema nyata sederhana dan identifikasi pencocokan gambar berdasarkan histogram warna seperti yang diusulkan oleh Swain dan Ballard . Dari penelitian ini , penulis menyimpulkan bahwa Speech SDK 5.1 kurang mampu mengenali intonasi disampaikan dengan tingkat akurasi yang diperoleh adalah keberhasilan rata-rata $75 \%+65 \%+90 \%=230 \%, 230 \% / 3=$ $76,67 \%$.

Kata Kunci: Suara, Warna, Pengenalan

\section{Pendahuluan}

Alat dalam komunikasi yang dapat menimbulkan hubungan interaktif merupakan sebuah Bahasa, terfokus dari human (manusia) antar human (manusia) yang dapat berinteraksi dengan sebuah bahasa tertentu, walaupun berbeda-beda. Bahasa tersebut tetap dapat diterjemahkan agar dapat dimengerti.

Teknologi pengenalan suara adalah teknologi yang menggunakan peralatan dengan sumber masukannya adalah suara, seperti microphone untuk menginterprestasikan suara manusia sebagai metode alternatif interaksi dengan komputer.[1]

Suara tak dapat merambat pada ruangan hampa udara. Gelombang suara ini memiliki lembah dan bukit, satu buah lembah dan bukit akan menghasilkan satu siklus atau periode. Siklus ini berlangsung berulang-ulang, yang membawa pada konsep frekuensi. Jelasnya, frekuensi adalah jumlah dari siklus yang terjadi dalam satu detik. Satuan dari frekuensi adalah Hertz atau disingkat Hz.[2]

Audio diartikan sebagai suara atau reproduksi suara. Gelombang suara adalah gelombang yang dihasilkan dari sebuah benda yang bergetar. [1]

Dalam menciptakan sistem yang dapat melakukan hubungan interaktif antara user dengan komputer, dapat diambil variabel suara yang berasal dari manusia yang diproses agar dapat dikenal komputer dengan melibatkan pola warna pada sistem komputer.

Maka masalah yang akan diangkat dan dibahas dalam studi kasus ini ialah bagaimana agar sistem komputer dapat mengenali suara yang berasal dari user (manusia). permasalahan tersebut dapat diatasi dengan mengimplementasikan SDK 5.1 untuk melakukan pemrosesan pengenalan suara dengan melakukan pencocokan suara melalui proses untuk mencocokkan kata ucapan yang berhasil diidentifikasi dengan pola warna yang dipunyai oleh sistem.[3]

Warna dapat memberikan informasi yang kuat untuk pengenalan objek. Sebuah skema real sederhana dan identifikasi dalam mencocokkan gambar berdasarkan histogram warna seperti yang diusulkan oleh Swain dan Ballard . [4] 


\section{Metode Penelitian}

Metode riset yang digunakan menggunakan metode ekperiment dimana metode ini menggunakan data secara mandiri dan data ekperiment dari beberapa jurnal.

\subsection{Perancangan Sistem}

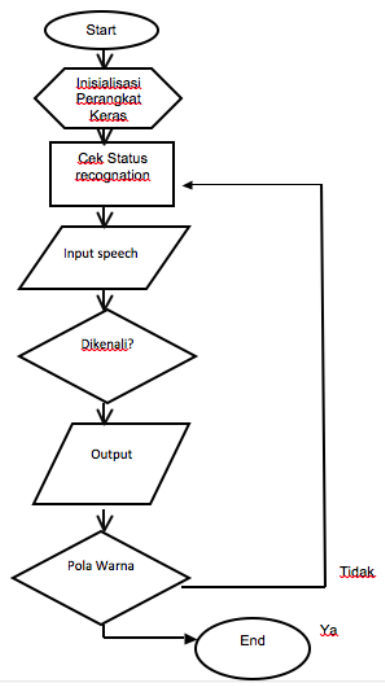

Gambar 1 Flow Chart Perancangan Sistem

\subsection{Blok Diagram}

Pada penelitian ini, peneliti membuat sebuah sistem yang mampu menginisialisai speech dan mengenal speech yang diinputkan oleh user speech yang yang diinputkan berupa 3 kata pola warna dasar yaitu Merah, Kuning dan Hijau. proses ini dapat diilustrasikan pada gambar 2.

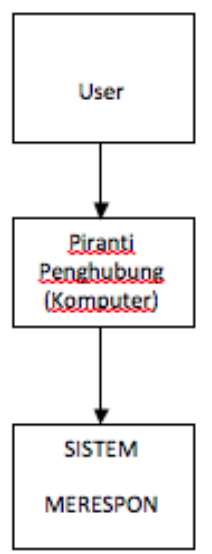

Gambar 2 Diagram Kerja Sistem

Pada sistem pengenalan pembicaraan, aplikasi akan menerima even pada saat suara yang diterima telah dikenali oleh engine :

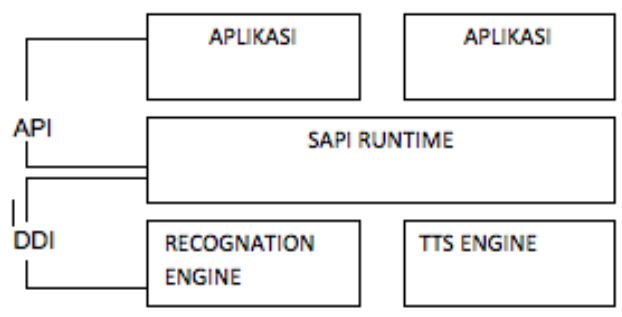

Gambar 3 Blok Diagram Engine

\subsection{Prinsip Kerja}

Prinsip kerja dimulai dari beberapa tahapan berikut :

1) Tahapan dimulai dengan proses inisialiasi engine pada sistem serta komputer sebagai piranti media perantara antara user dengan system.

2) Kemudian User mengecek status on recognition pada sistem, kemudian user menginputkan speech berupa tiga kata pola warna dasar yaitu Merah, Kuning dan Hijau.

Selanjutnya sistem akan melakukan proses pengenalan speech, dengan merespon sesuai speech yang diucapkan user dari salah satu tiga kata pola warna dasar yaitu Merah, Kuning dan Hijau, apabila warna red diucapkan maka warna merah akan menyala dan kuning dan hijau tidak menyala begitupun seterusnya.

\section{Hasil dan Diskusi}

\subsection{Hasil dan pembahasan}

Dari Hasil pengujian System dengan beberapa kali uji coba didpatlah hasil seperti yang tertera pada Tabel 1 dibawah ini:

\begin{tabular}{|l|l|c|c|c|l|}
\hline No & Variabel & $\begin{array}{l}\text { Banyaknya } \\
\text { pengujian }\end{array}$ & gagal & sukses & keterangan \\
\hline 1. & Yellow & 20 & $5(-)$ & $15(+)$ & $\begin{array}{l}15 / 20 \times 100 \% \\
=75 \%\end{array}$ \\
\hline 2. & Red & 20 & $7(-)$ & $13(+)$ & $\begin{array}{l}13 / 20 \times 100 \% \\
=65 \%\end{array}$ \\
\hline 3. & Green & 20 & $2(-)$ & $18(+)$ & $\begin{array}{l}18 / 20 \times 100 \% \\
=95 \%\end{array}$ \\
\hline
\end{tabular}

Tabel 1 Hasil Pengujian System

Hasil perhitungan :

Pada pola warna Yellow didapat jumlah pengujian sampel $=20$, Sampel $(+)=15$, Sampel $(-)=5$,Persentase keberhasilan $15 / 20 \times 100 \%=75 \%$ 
Hasil perhitungan :

Pada pola warna Red didapat jumlah pengujian sampel $=20$, Sampel $(+)=13$, Sampel $(-)=7$,Persentase keberhasilan $13 / 20 \times 100 \%=65 \%$

Hasil perhitungan :

Pada pola warna green didapat jumlah pengujian sampel $=20$, Sampel $(+)=18$, Sampel $(-)=2$, Persentase keberhasilan, $18 / 20 \times 100 \%=90 \%$

Dari Hasil perhitungan diatas didapatlah keberhasilan Rata-rata keberhasilan $75 \%+65 \%+90 \%=230 \%, 230 \% / 3=76,67 \%$.

\subsection{Pembahasan}

Pada sub bab kali ini akan dibahas rujukan dari hasil uji coba system diatas berdasarkan perhitungannya.

1) Untuk hasil uji coba yang dilakukan pada sampel pembicaraan (speeking) warna merah Kuning (Yellow) dari 20 kali uji coba kegagalan yang dihasilkan sebanyak 5 kali, karena intonasi dari kata yellow sedikit tidak dikenali saat diucapkan, kata yang didapatkan selama kegagalan adalah, "Yield", "You", "Young no", "You'll". Dari hasil dan juga pembahasan untuk perhitungan maka penulis berpendapat bahwa kata Yellow tidak dapat dikenali, dikarenakan ada huruf yang sama yaitu "LL" pada kata tersebut.

2) Untuk hasil uji coba yang dilakukan pada sampel pembicaraan (speeking) warna merah Merah (Red) dari 20 kali uji coba kegagalan yang dihasilkan sebanyak 7 kali, karena intonasi dari kata red sangat tidak dikenali saat diucapkan, kata yang didapatkan selama kegagalan adalah, "Read", "Write","Right”, “Leg”, "Rate”,'Let”, "Rec".Dari hasil dan juga pembahasan untuk perhitungan maka penulis berpendapat bahwa kata Red tidak dapat dikenali, dikarenakan banyaknya intonasi pada kosa kata bahasa inggris yang sama dalam pengucapan.
3) Untuk hasil uji coba yang dilakukan pada sampel pembicaraan (speeking) warna merah Hijau (Green) dari 20 kali uji coba kegagalan yang dihasilkan sebanyak 2 kali, karena intonasi dari kata Green mudah untuk diucapkan, kata yang didapatkan selama kegagalan adalah, "Great", "Gift". Dari hasil dan juga pembahasan untuk perhitungan maka penulis berpendapat bahwa kata Green tidak dapat dikenali, dikarenakan kurangnya penekanan huruf "n" pada kata tersebut

Dengan kesulitan dalam penerjemahan intonasi yang ada maka penulis menambahkan kata colour pada grammar program yang dibuatkan agar tidak menyulitkan user dalam penyampian intonasi dari tiga warna tersebut.

\section{Kesimpulan}

Dari penelitian ini penulis dapat menyimpulkan bahwa Speech SDK 5.1 kurang dapat mengenali intonasi yang disampaikan dengan tingkat akurasi yang didapatkan adalah Rata-rata keberhasilan $75 \%+65 \%+90 \%=230 \%$, $230 \% / 3=76,67 \%$.

Maka dari itu penulis memberikan Grammar bantuan pada program speech SDK 5.1 yang akan dipanggil pada program, bertujuan agar pengenalan pada intonasi user tercapai. Dan juga untuk pencapaian tujuan dari penelitian ini yaitu "komputer dapat mengenali perkataan (Speech) dari user".

\section{Referensi}

[1] Permadi Tareb, 2008. Pemanfaatan Microsoft Speech Application Programming Interface Pada Pembuatan Aplikasi Perintah Suara.

[2] Waluyanti Sri dkk, 2008. Teknik Audio Video.

[3] Noertjahyana Agustinus, 2003. Implementasi Sistem Pengenalan Suara Menggunakan SAPI 5.1 dan Delphi 5.0 berbasis Teks

[4] Gevers, Theo dkk. 1998. Color based object recognition in The Journal Of The Pattern Recognition Society.

[5] Septiari Resa ,2012 Konverter Suara Dengan Input Bahasa Indonesia Ke Video Gerakan Bahasa Isyarat Dengan Metode Speech Recognation (Hidden Markov Model) Untuk Penderita Tuna Rungu. 